\title{
CONDICIONES POLITICAS DE LA UNIVERSIDAD Y LAS NUEVAS HUMANIDADES. ITINERARIOS LATINOAMERICANOS REFORMISTAS Y CONTRARREFORMISTAS
}

\author{
POLITICAL CONDITIONS OF THE UNIVERSITY AND THE NEW \\ HUMANITIES. LATIN AMERICAN REFORMIST AND COUNTER- \\ REFORMIST ITINERARIES
}

\section{CECILIA SÁNCHEZ*}

Resumen: Me propongo reflexionar sobre la universidad y sus condiciones políticas actuales. Para la realización de este examen me detendré en su contexto moderno y contemporáneo, así como en los planteamientos que, desde las humanidades, defienden su autonomía frente al mercado, discutiendo también con el sexismo del saber y su lenguaje. Desde América Latina, considero algunos momentos paradigmáticos del itinerario de las universidades sobre la base de leyes, reformas, contrarreformas y prescripciones, desde la configuración positivista a la del neoliberalismo. Asimismo, para contrarrestar la condición colonial y sexista del saber considero algunas de las propuestas de las nuevas humanidades que se proponen ampliar la democratización del saber.

Palabras clave: Universidad, autonomía, Humanidades, colonialidad, transdisciplinariedad.

AвstRact: In this article, I set out to reflect on the University and its current political conditions. To carry out this task, I will delve into its modern and contemporary contexts, into the principles that, from the Humanities, defend its autonomy vis-à-vis the market, as well as into the sexism of knowledge and its language. Within the Latin American context, I consider some paradigmatic moments in the itinerary of Universities based on laws, reforms, counter reforms and prescriptions, from the positivist configuration to neoliberalism. Likewise, to counteract the colonial and sexist condition of knowledge, I take into consideration some of the proposals of the new humanities that aim to expand the democratization of knowledge.

KeYwords: University, Autonomy, Humanities, Coloniality, Transdisciplinarity.

Recibido: 2019-07-23. Aceptado: 2020-04-25.

* Doctora en Filosofía. Académica de la Universidad Academia de Humanismo Cristiano, Santiago, Chile. Correo electrónico: cecisanchez0@gmail.com. Orcid: http://orcid.org. 0000-0002-9543-9264. 


\section{APRECIACIONES INICIALES: LOS CONTRA-TIEMPOS DE LA UNIVERSIDAD}

Y

A DESDE EL PERÍODO de inicio de la investigación sobre la configura-

ción universitaria de la filosofía en Chile, publicado en Una disciplina de la distancia (Sánchez, 1992), la universidad se me apareció como un problema, así lo referí al finalizar la "Presentación" del libro. Se trata de ese tipo de problemas cuya manifestación es por ausencia. Como se sabe, en el período de la dictadura cívico-militar se emiten decretos y procedimientos para intervenir y luego cambiar el giro del modelo de las universidades chilenas, adscritas al proyecto público de la nación. Además de intervenir mediante censuras y prohibiciones, la dictadura propina uno de los golpes más nefastos a la universidad y la educación pública; modela un tipo de universidad y de educación gerencial de corte neoliberal, muy diferente a la "idea" o "misión" de la "universidad", según la propuesta de Jorge Millas (1981). Además de privatizar el ingreso, el giro que sufre la universidad trastoca la temporalidad de sus reflexiones. En el "Prólogo" al libro de Maximiliano Figueroa, titulado Jorge Millas. El valor de pensar, Humberto Giannini (2011) defiende la temporalidad de la universidad como un "contra-tiempo", cuya temporalidad va "contra el reloj de la acción impulsiva o del slogan" (p. 25). Con esta noción alude tanto a la extrema ideologización de las consignas de la izquierda estudiantil como a la rápida vinculación con el mercado, dado que se trata de un tiempo "diverso del mero pasar", entendiendo que este es "el tiempo de la Universidad" (pp. 25-26). A la inversa, desde la universidad gerencial, configurada en Chile desde los criterios del neoliberalismo de la así llamada Escuela de Chicago, asociada, asimismo, al principio de subsidiaridad de la Constitución del 80, se sostiene que los sistemas educacionales son mejores cuando operan bajo los mismos criterios competitivos que las empresas. De esta manera, la familia puede elegir -al modo en que se elige en un supermercado- el colegio o la universidad más eficiente para sus hijos/as. De acuerdo a este modelo, el tiempo de la reflexión es el tiempo del homo economicus, establecido a partir de una moral comercial que favorece la productividad vinculada al mercado. Si bien es propio de la universidad mantener un conflicto en torno a los tiempos, los productos y a los públicos desde y a los cuales se dirige, como lo hace ver Kant en sus textos sobre la universidad, según veré en el siguiente apartado, en la universidad gerencial este conflicto se suprime, ya mediante la eliminación o vigilancia de las disciplinas más autónomas y críticas, o bien haciéndolas funcionar desde la misma lógica comercial. Como bien lo indica Cristóbal Friz (2016), desde 
el neoliberalismo de Friedrich Hayek se espera la inobjetabilidad del orden social regido por el mercado, por lo mismo se recela de los "intelectuales críticos" (p. 70). Dada la importancia de las humanidades para que la universidad pueda democratizarse, considerar los derechos humanos y abrirse a procesos sin puntos fijos, también para cuestionar el sexismo, el colonialismo y la profesionalización, nos detendremos en una propuesta sobre lo que podría entenderse como "nuevas" humanidades.

Para abordar desde una perspectiva crítica el modo en que el progreso material del conocimiento se disocia del principio moral de la autonomía y no permite el "contra-tiempo" invocado por Giannini, habría que narrar una compleja historia sobre el tipo de relación que mantiene la universidad con el poder político en América Latina. Por lo general, la historia de las universidades latinoamericanas y, más particularmente, la de aquella que fabricó la dictadura en Chile, ha quedado cubierta bajo el pesado manto de la Historia con mayúscula de lo que se ha entendido por universitas. En este artículo me interesa dar cuenta de algunos de los trazos y devenires de las disputas que, en América Latina oponen, primero, el pensamiento científico de corte positivista al modernismo poético-político; posteriormente, examino la reforma de la Universidad de Chile y la "contrarreforma" que tuvo lugar en la Universidad Católica, según denomina Luis Scherz (1988) al movimiento universitario vinculado a la Escuela de Chicago y a la participación de civiles provenientes de la Universidad Católica en el gobierno militar. La historia que refiero se cruza con la disolución del intra-espacio arquitectónico-político de la universidad a raíz de las deslocalizaciones y fragmentaciones producidas por el crecimiento de los medios digitales y por su sumisión a las solicitudes del mercado global. En esta línea, cabe citar al filósofo francés, Bernard Stiegler (2012), quien al referirse a la "destrucción de la educación pública" de parte del capitalismo hiperindustrial pone como ejemplo las privatizaciones operadas por Augusto Pinochet, Milton Friedman y la Escuela de Chicago (p. 17). Con esta cita avalo que hablar de Chile no es hablar de un fenómeno local con respecto al neoliberalismo; todo lo contrario, es la puesta en marcha global del pensamiento y la educación neoliberal más radicalizadas.

\section{LA UNIVERSIDAD Y EL CONFLICTO POR EL LIBRE JUICIO}

Desde un punto de vista político, se habla de "entrar" a la universidad, sin detenerse mucho en lo que significa "entrada", "interior" o "afuera", espe- 
cialmente cuando varias de las investigaciones en tecnologías de la información son realizadas por multinacionales como Microsoft. Este aspecto lo hace notar Santiago Castro-Gómez (2017) diciendo: "El conocimiento que es hegemónico no lo produce ya la universidad bajo la guía del Estado, sino que lo produce el mercado bajo la guía del mismo" (p. 75). Pese a todo, todavía se considera a la universidad como el lugar de mayor validez para la producción de conocimientos y obtención de títulos, aunque esa validez no existe sin un principio de autonomía o de independencia. Con respecto a este principio, Plinio Prado (2009) señala:

Este principio es decisivo. Permite que el pensamiento escape de una convivencia embrutecedora con los "hechos", para disponer de la perspectiva necesaria para cuestionarlos, analizarlos y juzgarlos -es decir, criticarlos de acuerdo con sus propias exigencias- y, por consecuencia, no ceder ante la evidencia brutal de la "realidad". (p. 9, trad. propia) ${ }^{1}$

Este tipo de validación es de carácter moderno, puesto que no separa el progreso material del progreso moral; además porque distingue entre conocimiento legítimo e ilegítimo, de acuerdo a reglas internas que permiten juzgarse entre pares, sin la intromisión de un poder externo. En esta distinción contribuye de manera decisiva el pensamiento de Kant (ver 1963), conocido como el filósofo de la autonomía universitaria y de la Aufklärung. En su osado escrito El conflicto de las Facultades, publicado en 1798, el filósofo alemán define la organización de la universidad como el lugar topográfico en donde la sociedad erudita desarrolla un conflicto permanente en nombre del concepto de la razón. El conflicto es entre las Facultades Superiores (Medicina, Derecho y Teología), regidas por la racionalidad de la naturaleza (Medicina), el poder legislativo (Derecho) y la gracia divina (Teología), cuyos saberes se destinan a un público; y las Facultades Inferiores, regidas por el libre juicio, sin buscar satisfacer a ningún público. Tal es la situación de la Facultad de Filosofía, compuesta de dos departamentos: el de los conocimientos históricos (historia, geografía, filología científica, humanidades) y el de los conocimientos racionales (matemática, filosofía, metafísica de la naturaleza y de las costumbres). Si atendemos a este tipo de

\footnotetext{
${ }^{1}$ Es importante señalar que este libro surge en Francia a propósito de la "reforma" de la universidad y del movimiento de resistencia desarrollado en algunas universidades durante el gobierno de Sarkozy entre 2007-2009. Según Prado, se trata de oponerse al capitalismo liberal, la tecnociencia y la mercantilización del conocimiento levantando el principio de independencia y de responsabilidad de la universidad.
} 
conflicto, podría decirse que la universidad de nuestra época responde a la escena de confrontación entre el mercado y el ejercicio del juicio.

En el caso de la concepción kantiana de la universidad, la querella es entre el despotismo del Estado y la razón. Bien se sabe que Kant experimentó las prohibiciones de Federico-Guillermo II, quien defiende la ortodoxia de la Iglesia en contra del discurso de la ilustración. En el prefacio de este libro, Kant explicita la censura de la que fue objeto su libro La religión en los límites de la propia razón, esgrimiendo que sus argumentos van dirigidos a un público universitario cuyas normas son autónomas con respecto de las prohibiciones provenientes del mundo político. Con esta señal demarcatoria entre un interior y un exterior de la universidad comienza el libro. Diez años más tarde, Fichte y Humboldt confirman esta idea racional de la universidad y su progresivo perfeccionamiento de la humanidad ideal con la fundación de la Universidad de Berlín. Para Jacques Derrida (1984), el modelo formulado por Kant desde la equivalencia entre razón y justicia va a ser el modelo de la "moderna Universidad en general" (p. 29). De acuerdo a lo dicho, se podría preguntar: ¿existió alguna vez este tipo de racionalidad libre? Si la respuesta es afirmativa, la pregunta es si tenemos hoy una universidad racional en los términos morales en que fue planteada. Desde un autor como Claudio Bonvecchio (1991), la respuesta es que la universidad añorada es un "mito" producido por el mundo burgués, cuyos efectos metafóricos persisten hasta hoy. Autores como Lyotard (1989), Derrida (1984 y 2010), y Castro-Gómez (2017) también han dado una respuesta negativa. Tras la derrota del metarrelato del progreso, reconocen que las rentabilidades tecno-políticas del saber actual desbordan los límites topográficos y morales de la universidad moderna ${ }^{2}$.

\section{DEMOCRATIZACIONES DE LA UNIVERSIDAD EN AMÉRICA LATINA}

En las universidades latinoamericanas han caído imposiciones que vienen del lado de instituciones y regímenes dictatoriales que adoptan modelos de universidad afines a sus ideologías. Es curioso, pero el suceder de episodios,

\footnotetext{
${ }^{2}$ A propósito de la concepción moderna de la Universidad y de su "crisis", el libro La crisis no moderna de la universidad moderna, de Willy Thayer (1996), es de suma importancia para pesquisar su trama desde el gran relato europeo sobre la universidad y sus vertientes, pero falta ligar este relato con las políticas de las universidades en América Latina y su giro post-estatal o pro mercado, especialmente en Chile, sobre la base de los postulados de la sociedad del conocimiento.
} 
crisis, reformas y contrarreformas por las que atraviesan las universidades en estas latitudes se rige principalmente por decretos, leyes y reglamentos - la mayoría de carácter impositivo-; en vez de generar debates a partir de los cuales se perfilen correcciones o nuevos modelos del saber.

Con respecto a nuestra condición de asimiladores o traductores de modelos culturales de los centros del poder, Santiago Silviano (2012) hablará de "asimilación inquieta o antropófaga" (p. 69); en este acto incluye a los escritores o pensadores de una cultura dominada que se instalan en un "ya dicho" o "ya escrito". De ahí que lo importante es apreciar las mediaciones silenciosas, traducciones y traiciones al texto al que se refieren. Dicho esto, es importante dejar en claro que, desde la fundación del Nuevo Mundo, cabe hablar de un ordenamiento letrado del saber. Uso la noción de "letrado" en el sentido que le entrega Ángel Rama (2004), debido a que Iberoamérica queda inscrita en una concepción de la cultura que Europa considera "universal". Desde el modelo de la letra, puede decirse que la filosofía implícita por la que dicha instalación se rige proviene de los supuestos de una "humanidad universal", proclamada por el pensamiento letrado-iluminista. Desde las categorías que la acompañan, se reclama un derecho a las letras y al pensamiento bajo el supuesto de que el intelectual iberoamericano es un participante sin más de la cultura occidental, ignorando su "lado oscuro" (Mignolo) (2017), su "colonialidad" (Quijano, 2014) o la "geopolítica del conocimiento" (Mignolo, 2003).

Este planteamiento asimilador del saber se deja ver con claridad en Andrés Bello a propósito del modo en que articula un trabajo intelectual de carácter nacional e hispanoamericano en la Universidad de Chile, haciéndolo consistir principalmente en la "aplicabilidad" de los saberes difundidos por las así llamadas "luces". En su discurso fundacional de la Universidad de Chile, Bello sostiene que esta institución ha sido establecida para "recibir" y "propagar" los beneficios de este saber universal: “... el programa de la Universidad es enteramente chileno: si toma prestadas a la Europa las deducciones de la ciencia, es para aplicarlas a Chile" (Bello, 1843, pp. 139-152). Bajo la inspiración de la "filosofía de la Universidad" de Victor Cousin, que según Patrice Vermeren (2009) va de la mano de Hegel para justificar el orden establecido, la autonomía de la Universidad de Chile se supedita a los cometidos de su patrono, el Presidente de la República, quien nombra a los catedráticos, rectores y funcionarios. Estos serían los letrados o burócratas modernos, constituidos como ejecutantes del mandato del "Estado educador". Esta concepción de un "saber imparcial" (Vermeren, 2009, p. 38) o del “justo medio" (Ruiz, 1975), sobre la que Ángel Rama (2004) reflexiona en 
La ciudad letrada, persiste hasta hoy en las universidades latinoamericanas, uno de cuyos efectos es la enorme distancia entre la lengua pública y la lengua de la plebe.

Posteriormente, desde Comte, Littré, Mill, Spencer, entre otros, emana un pensamiento configurador de la política que lo convierte en el pensamiento del Estado y de la nación a partir de un discurso pedagógico unificante, pese a que tal situación lo hace entrar en contradicción con sus principios universalistas. Bien se sabe que el positivismo comteano es una de las variantes más apreciadas por los intelectuales iberoamericanos en su forma de categorización de la sociedad y de la universidad. Se trata de una doctrina común proveniente de las ciencias, producida por un intelecto público cuyo domicilio es la universidad, cuya finalidad es ponerle fin a las fluctuaciones intelectuales y políticas. En Chile, Valentín Letelier (1912) cita a Augusto Comte para defender la unidad de criterios entre universidad y gobierno. En su Filosofía de la Educación sostiene: "Según lo observa Augusto Comte, no hai gobierno posible sin unidad de miras (a v). Si la autoridad docente ni difunde un mismo espíritu en toda la enseñanza i en todas partes, las contradicciones la desconceptúan i su ascendiente moral se amengua" (p. 549). En México, el orden para dominar la "anarquía social", leída así a partir de Comte, termina por identificarse con el "Porfirismo" (Zea, 1968, pp. 48-50). En Uruguay, el positivismo se orientó principalmente hacia el evolucionismo sajón de Darwin y de Spencer; Comte, por el contrario, no encontró seguidores en este país. Sea quien sea el autor que lo vehiculice, es común en los países adeptos al positivismo la adopción de una concepción de la ciencia subordinada a los requerimientos tecnológicos-industriales como condición de un profesionalismo cuyo aspecto utilitario empieza a resultar vulgar y decadente desde fines del siglo XIX.

El desencanto con el positivismo es bastante amplio en América Latina, pero a nivel universitario se expresa de modo paradigmático en la Universidad de Córdoba de Argentina, fundada en 1613 por los jesuitas. Marginada del mundo moderno y con miembros vitalicios, la Universidad de Córdoba se convulsiona en 1918 con la Reforma Universitaria. Se dice que primero fue crítica de las estructuras de poder tradicionales, aunque ostentara variadas perspectivas. Desde el punto de vista de Jorge Las Heras (2009), a partir de 1908 los estudiantes latinoamericanos se agrupan para obtener representación en los gobiernos universitarios. A raíz de la Reforma, la Universidad es intervenida buscando la democratización en la designación de sus autoridades y el cogobierno. Las Heras recalca que los estudiantes argentinos en general solidarizan con la Reforma de Córdo- 
ba, además de condenar el militarismo, respaldan la Revolución Rusa, los movimientos obreros, la asociación Feminista Nacional, entre otros perseguidos o excluidos (p. 31). A su vez, este afán reformista repercute en Perú bajo términos semejantes a las demandas de los estudiantes en Argentina, en contra de la perennidad de las cátedras, exigiendo representación en el Consejo Universitario, asistencia libre a clases, incluyendo la creación de las "Universidades Populares González Prada" (p. 58), que contaban con el apoyo de José Carlos Mariátegui.

Con todo, la Reforma rebasa el hecho pedagógico. Las Heras (2009) señala que Augusto Salazar Bondy asume esta perspectiva y entiende que esta agitación social reconoce cambios en la expansión del capitalismo, entre otros aspectos (p. 82). A nivel de sus propuestas, es importante resaltar que este movimiento repelió al positivismo, asociado, según Las Heras, al "progreso", al "confort" y al "utilitarismo" (p. 86). En esta óptica influye la corriente modernista de fines del siglo XIX y comienzos del siglo XX, entre cuyos representantes se cuenta a Rubén Darío y José Enrique Rodó. Estos escritores desacreditaron el materialismo utilitario metaforizado por la así llamada "alma apetitiva de Estados Unidos", expresión tomada de la República de Platón, reivindicando una cultura humanista y sensible (Sánchez, 2015, pp. 52-53). En concordancia a lo planteado, el así llamado "arielismo" (Rodó), incluido el "iberismo" y "latinismo" (Darío), son expresiones que, además de oponerse a un "sajonismo invasor" o "calibanismo positivista" de corte norteamericano, como los denomina Eduardo Devés (2000, p. 27), son reivindicaciones de un pensamiento cuyo contexto es América Latina.

\section{REFORMAS Y CONTRARREFORMAS UNIVERSITARIAS EN CHILE}

Si bien Chile participa de lejos en este debate, la modernización es una piedra de toque en las universidades chilenas debido a que incorpora una nueva forma de institucionalidad profesional, de acuerdo con el modelo tecno-económico producido en las sociedades capitalistas de mayor desarrollo. Si anteriormente el modelo positivista había consistido en el "progreso", de acuerdo con el marco establecido por la modernidad europea en los términos de civilización/ barbarie, todavía compatible con el binarismo del progreso/retraso que incluía el aspecto moral, tras la Segunda Guerra Mundial se empieza a administrar la jerárquica y secuencial denominación 
Primer, Segundo y Tercer Mundo. De este modo, en vez de la alternancia progreso/retraso, la nueva racionalidad de la modernización proviene de los criterios norteamericanos y se mide a partir del binarismo del desarrollo/subdesarrollo, cuyos índices son los del bienestar y la funcionalidad de las estructuras. En este contexto, una de las disciplinas que se profesionaliza es la sociología, siguiendo las pautas tecnocráticas que también fueron adoptadas por la CEPAL (Brunner, 1986).

He mencionado el nuevo tipo de lenguaje que asume la racionalidad modernizante de los años 50 para abordar algunos de los modelos de universidad puestos en juego en las reformas y contrarreformas universitarias, que estudiantes, profesores y sistemas políticos llevaron a cabo en ocho universidades chilenas durante las transformaciones generalizadas que los gobiernos de Eduardo Frei Montalva y Salvador Allende ponen en marcha. Me interesa atender a estas transformaciones debido a sus impactos políticos en Chile y por ser la "Contrarreforma", término usado por Scherz (1988, p. 44) para aludir a la Universidad Católica durante el período de la dictadura, la propiciadora del modelo neoliberal y de una "sociedad del conocimiento".

Luis Scherz (1988) es uno de los estudiosos de este acontecimiento en las universidades católicas, destacando especialmente la disputa por el aspecto modernizante de la Universidad, a la vez que ofrece el punto de vista neoliberal de la que él denomina "Contrarreforma". Con respecto al desarrollo de la Reforma en las universidades católicas, Scherz también incluye el papel activo que llegó a tener la teología y la crítica a los aspectos tradicionalistas y profesionalizantes de la universidad. De este modo comienza el "modernismo de las calles", como lo llama Berman (1998) a propósito de la modernidad y su carácter subversivo (p. 20), y los estudiantes empiezan a tener protagonismo en Chile con ocasión de la Reforma. En 1967, las organizaciones estudiantiles explotan en contra de "las torres de marfil", "muros", "clasismos" e "instrumentabilidad" de la universidad, postulando una apertura a los cambios sociales que se discuten en el país (p. 38). En contra del profesionalismo, se postula primero el modelo humboldtiano. Contiguo a este modelo, se postula el rol transformador y social de la universidad, siendo este último el que predomina. Según Scherz (1988), los estudiantes gremialistas ocupan las posiciones antagonistas en este debate; son quienes denuncian a la extrema politización de los reformistas (p. 39). En este contexto, es importante mencionar un proyecto sin el cual no se entiende el período de la dictadura y el auge del neoliberalismo: me re- 
fiero al desarrollo de una experiencia piloto en la Escuela de Economía y Administración, propiciado en pleno período reformista por la así llamada "Escuela de Chicago", de la Universidad de Chicago. Este piloto recibe financiamiento del Banco de Desarrollo (BID) y de las fundaciones Ford y Rockefeller (p. 39). Con el levantamiento de este proyecto, se puede advertir que el modelo que termina triunfando en la Universidad Católica es el modernizante, operando sobre la base de la subordinación de lo académico al dominio de lo administrativo y técnico.

En el caso de la Universidad de Chile, el emblema del reformismo es convertir a la universidad en "agente del cambio social", intentando remover la orientación modernizante que entiende al conocimiento como "factor de producción" (Sánchez, 1992). Es importante destacar que uno de los logros del movimiento reformista consistió en la resignificación del papel del profesor que, de docente reproductor de conocimientos, pasa a incorporar la investigación. Este aspecto forma parte de los "Acuerdos de la Convención de la Reforma Universitaria, FECH, 1967” (p. 159). La disputa por la figura que debía asumir la "universidad participativa" oscila entre una "universidad pluralista, crítica y comprometida" y otra "militante". Esta pugna, al igual que en la Universidad Católica, se agudiza en 1970 con el triunfo de Salvador Allende. En los departamentos de filosofía, hay al menos tres figuras que se confrontan: Humberto Giannini, Juan Rivano y Jorge Millas. En estos tres casos, los estereotipos abundan. Giannini ha testimoniado en varios de sus escritos y entrevistas en periódicos acerca del ambiente intolerante del período, siendo acusado de "profesional" junto con Millas; en cambio Rivano aparece como el "crítico" del período, según el estudio sobre la filosofía en Chile realizado por Iván Jaksic (1989). Sin embargo, Giannini (2015) también ha defendido la impugnación que se le hizo a la "universidad profesionalizante" y ha apoyado el levantamiento que algunos grupos hicieron del humanismo. En el caso de Jorge Millas (1981), varias de sus posturas sobre la universidad se pueden leer en Idea $y$ defensa de la universidad. Ante el dilema de optar entre una universidad del pueblo o una burguesa, para Millas la única opción es el desarrollo del saber guiado por la "razón", tratando de responder de modo kantiano a la pregunta por la "idea absoluta de universidad", en oposición a la "extroversión"; término que toma del pensamiento de José Ortega y Gasset sobre la universidad y que reinterpreta como una simple opinión o curiosidad de quienes no han pensado suficientemente un tema. Es importante señalar que de este período reformista y sus conflictos se pasa abruptamente a la nueva lógica inaugurada por el golpe de Estado. 
1973 es el año de la suspensión del Estado de Derecho y de los más severos quebrantamientos de los derechos humanos mediante las "depuraciones" practicadas por la Doctrina de la Seguridad Nacional, a la par que de la introducción del neoliberalismo. El momento de la suspensión del Estado de Derecho convierte a la universidad en "vigilada", según el nombre que oportunamente le entrega Millas (1981). También cataloga a la universidad de "alienada", debido a que pierde su propio centro. Ahora un poder extraño toma su control bajo la figura de los Rectores Delegados ( $\mathrm{p}$. 133), entre los que se cuenta el tristemente célebre José Luis Federici, quien intenta aplicar en la Universidad de Chile una política económica extrema, siendo removido de sus funciones a los dos meses de su nombramiento a raíz de un paro que reactiva el movimiento de oposición al régimen. Con la introducción del neoliberalismo en la sociedad chilena y en la educación, la "misión" y la "idea", de la universidad de la que habla Millas, queda por completo fuera de lugar, especialmente con la exigencia de autofinanciamiento que tiende a igualar a la universidad a una empresa privada. Bajo esta nueva condición, los viejos valores de la "libertad académica" y de la "autonomía universitaria", nombrados en la legislación dogmática de la nueva Ley de Universidades decretada en 1980, pasan a ser, según Millas, pura "retórica". Habría que decir que la nueva ley permite la creación en Chile de universidades privadas desde una nueva institucionalidad ${ }^{3}$. Esta permite fijar aranceles con precios de mercado, facilidad que en poco tiempo permite pasar de ocho a cincuenta y nueve universidades. El comienzo desregulado de las nuevas universidades privadas, tanto en su calidad como en sus exigencias económicas, ha tenido efectos negativos en el egreso masivo de alumno/as con muy mala formación, salvo excepciones. Recién en 1999 se inicia un proceso de acreditación de mejoramiento de la calidad, derivando en 2006 en la creación de la Comisión Nacional de Acreditación, CNA, siendo resistida por el sector más neoliberal, entre otros, el Instituto Libertad y Desarrollo (Basso, 2016, p. 28).

En relación con la introducción del neoliberalismo en Chile, recordemos la cooperación entre la Escuela de Chicago y la Escuela de Economía de la Universidad Católica, gestada en medio de la Reforma de la institución católica, según lo hace saber Scherz en su repaso sobre la reforma y la contrarreforma. De acuerdo con este examen, cuando los civiles comienzan a

\footnotetext{
${ }^{3}$ Se permitió la creación de universidades privadas a partir del DFL N² 2 , del Ministerio de Educación, promulgado el 30 de diciembre de 1980, pero publicado en el Diario Oficial el 7 de enero de 1981. Ver Basso (2016).
} 
participar en la nueva institucionalidad creada a partir del Golpe Militar, la conducción de la política económica es asumida por los profesionales formados en la Universidad Católica y en la Universidad de Chicago. De este modo, el humanismo cristiano se trasmuta en el mercado libre y, habría que agregar, consigue "impactar" (según se mide hoy a la investigación y a la productividad universitaria en general) en la sociedad completa.

Es importante advertir el modo en que en este período las humanidades son repelidas por parecer peligrosas o, en el menor de los casos, se ven como un mal que debe ser "tolerado", como ocurre con la filosofía (Sánchez, 1992). Scherz nos hace saber que las disciplinas o profesiones favorecidas por la dictadura y por la nueva óptica de la economía son las carreras tecnológicas, junto con la agronomía, ingeniería y la medicina, entre algunas ciencias naturales (p. 50). En cambio, las carreras de las ciencias sociales y las humanísticas se cierran, reducen o vigilan. Un testimonio de la situación de las humanidades y las pedagogías durante la dictadura la entrega Javier Pinedo, quien fuera el director del Instituto de Humanidades de la Universidad de Talca. En una de sus últimas entrevistas dada a uno de sus alumnos (Díaz, 2018), da cuenta de la deslegitimación y relegitimación de las humanidades y de las universidades regionales. A continuación, examino parte de su relato.

\section{POLÍTICAS DE LAS “NUEVAS” HUMANIDADES EN UN RÉGIMEN TRANSDISCIPLINARIO, NO SEXISTA Y DESCOLONIZADO}

A propósito de la pregunta acerca de cómo se funda la revista Universum, Pinedo relata los últimos años de la dictadura y su impacto en el contexto educacional nacional y local. La Universidad de Talca es profundamente afectada en estos años, porque su último rector delegado, Guillermo Monsalve, procede a cerrar las pedagogías y las humanidades, abriendo carreras consideradas "superiores" (ver Díaz, 2018, p. 237), entre ellas, agronomía y derecho. El cierre de las pedagogías, en su mayoría humanísticas, se debía a que no estaban en la lista de las doce carreras de prestigio internacional, de acuerdo con el criterio de lo que el gobierno militar entendía por universidad. Para Pinedo, este cierre es sumamente grave, en especial porque sostiene que en las provincias la inteligencia que puede pensar Chile proviene de los profesores y, en esa esfera, de los escritores, poetas, cuentistas y ensayistas. Bajo el nombre de pensadores y ensayistas nombra a Alejandro Venegas y a Enrique Molina (este último sería el fundador de la Uni- 
versidad de Concepción). Antes de relatar la disolución de las sedes de la Universidad de Chile en las regiones bajo la dictadura, explica que deben su existencia al "Plan California", cuyo modelo es la "Universidad de California, Los Ángeles". Desde los parámetros del College norteamericano, la Universidad de Chile se descentraliza durante el gobierno de Eduardo Frei Montalva ${ }^{4}$. De este modo, se fundan "Colegios Regionales" en la Serena, Iquique, Tarapacá, Talca, Chillan, Osorno, La Frontera, entre otros. En 1981, estos institutos regionales se independizan y se transforman en Institutos Profesionales. El problema subrayado por Pinedo es que al perder las pedagogías, la Universidad de Talca pierde su conexión con las humanidades y su proyección como Universidad. Por este motivo, para constituirse en una Universidad las autoridades piden consejo a la Universidad Ezra Cornell, de Nueva York. Pinedo relata que frente a la situación de una universidad sin humanidades los académicos norteamericanos señalan en un informe: "Error, ustedes nunca van a hacer nada importante si no tienen un área de humanidades y ciencias sociales" (p. 243). A propósito de este consejo, Pinedo opone el modelo napoleónico, más disciplinario, al norteamericano, proclive al intercambio disciplinario. En definitiva, el modelo de universidad al que aspira Pinedo es el que relegitima a las humanidades sobre la base de una flexibilización del modelo profesionalizante. Con todo, habría que precaverse de no caer en el modelo de las universidades organizadas únicamente para servir al mercado global, carentes de "contra-tiempo", según entiende Giannini el tiempo de la universidad y, agreguemos, del ethos de la academia, que suponía detenciones para hacerle espacio a discusiones y debates de índole ético-estético-político.

Con todo, a varias décadas del fin de la dictadura, las humanidades mantienen su repliegue e invisibilización: reciben menos presupuesto a nivel de la investigación, se les imponen las mismas reglas de escritura que a las disciplinas científicas bajo la modalidad del paper, cuyo efecto es interferir en los tempos del pensamiento y la escritura (Sánchez, 2010), a la vez, que se controla lo escrito mediante criterios organizacionales (Santos Herceg, 2012). Asimismo, las humanidades son escasamente consideradas dentro de las nuevas políticas del conocimiento del recientemente instituido $\mathrm{Mi}$ nisterio de Ciencias, Tecnologías, Conocimiento e Innovación. El hecho de que el neoliberalismo se deshaga de las humanidades, debido a que su dis-

\footnotetext{
${ }^{4}$ Entre los participantes en esta nueva institucionalidad se encuentran Irma Salas y los rectores de las Universidades de Chile y la Universidad Técnica del Estado (Juan Gómez Millas y Horacio Andaur) y el presidente Frei Montalva, en el contexto de la Reforma Universitaria entre 1967 y 1968 . Ver Pinedo (2012).
} 
curso es más crítico, en gran parte se explica por el deseo de avanzar hacia lo que pomposamente se ha denominado "sociedad de conocimiento". Este modelo también busca superar a la universidad profesionalizante y lineal, pero su principal cometido es que los perfiles de egreso se conecten con los mercados laborales de una manera más dinámica. La meta es no perder tiempo al momento de incluirse en el ritmo del mundo global, en contraste con la lentitud de las universidades tradicionales (Didriksson, 2014, pp. 550-553). Desde esta perspectiva del conocimiento, el modelo de universidad recomendado es uno que interactúa con la industria transfiriendo conocimiento e investigación aplicada, cuyos actores principales serían quienes forman parte del "capital avanzado". ¿Cómo resistir estas imposiciones?

De acuerdo con lo expuesto, urge recuperar a las humanidades, pero transformadas. Las de corte tradicional todavía mantienen límites conceptuales que las incapacitan para ampliaciones democratizadoras de mayor envergadura. Una posibilidad es preguntarse por las "Humanidades del mañana", como las llama Derrida (2010, p. 9). A mi juicio, es importante hacer ver que Derrida sitúa el horizonte de las "nuevas" Humanidades en la "mundialización", referida a una humanización, y no a la "globalización", que privilegia al mercado. Del planteamiento de Derrida me interesa destacar que, como lugar de resistencia al mercado y otros poderes, a estas nuevas Humanidades les cabe el cuestionamiento no solo de la "democracia", también de la "idea tradicional de crítica" (p. 14). Solo así se puede hablar de una "universidad sin condición" frente a los poderes que la acechan, es decir, conformada como una "universidad absolutamente independiente". Como único vínculo con las Luces o ilustración, invoca al "espacio público" kantiano y su derecho a decirlo todo públicamente. Así planteada, esta universidad no tiene un dentro resguardado; está en el mundo que trata de pensar.

Esta propuesta de signo performativo vinculada a la "deconstrucción", cuestión que he omitido por falta de tiempo, tiene como problema su delimitación geopolítica, pues sigue estando muy ligada al pensamiento europeo y a su verticalidad, sin reparar en algunos de los poderes introyectados en el saber, como el colonialismo, el sexismo y el patriarcalismo. En mi opinión, considerar estas marcas del saber permite establecer la interrogación por las humanidades desde lugares más abiertos y democratizadores. A modo de ejemplo, refiero la cita de Zulma Palermo (2017) de la exclamación de Franz Fanon como una apertura desde el cuerpo: “iOh cuerpo mío, haz de mí, siempre, un hombre que interrogue!” (p. 17). Así, la interpelación y cuestionamiento al saber funcional de la sociedad del 
conocimiento no es solo a nivel del pensamiento; también es recuperarse de diversas deshumanizaciones localizadas en el cuerpo, a veces borradas por las nuevas formas del universalismo, por las colonialidades externas e internas provenientes del habla, la escritura y de una larga política colonial y sexista. En la resignificación de las humanidades, lo humano y las claves de la normalidad a las que el saber moderno nos tenía acostumbrados/as quedarían cuestionadas, debido a que estamos en la época de las transiciones. Rosi Braidotti (2004, pp. 39-45) toma en cuenta a autores y autoras contemporáneos/as como Deleuze e Irigaray, entre otros/as, para hablar de procesos sin puntos fijos, de devenires y otredades antes expulsadas del saber o devaluadas. De este modo, se crean y se aceptan nuevas formas de diferencias de lo humano que ponen en crisis la idea moderna de Hombre. Para Luce Irigaray se trata de "lo mismo", para Gilles Deleuze de lo "mayoritario", un falso universal por contraste con lo "menor"; mientras que, para Preciado, la transición es tecnológica. Bajo estas coordenadas es que ahora puede plantearse un nuevo régimen del saber transdisciplinario también en las áreas de las ciencias naturales (Castro-Gómez, 2017), que puedan ser receptivas a las teorías feministas y a las denuncias contra la colonización y al antropologismo negador de la naturaleza. En este sentido, descolonizar y desarborizar el saber es ahora acercarse a la doxa, a saberes ancestrales, a corporalidades plurales, posibilitando el descongelamiento de lo que por largo tiempo fue rotulado de bárbaro o pasional. Bajo estas nuevas coordenadas se podría recuperar el conflicto del que vive la universidad para generar los debates que deben tener lugar en universidades situadas en el mundo. Las humanidades serían, así, "mundiales" antes que universales, dicho al estilo de Dussel para validar a todas las culturas. Por cierto, las propuestas de estas nuevas humanidades serían actos o invocaciones, antes que constataciones o reglamentos que caigan desde el poder mercantil o estatal a la universidad.

\section{REFERENCIAS}

Basso, P. (2016). Educación Superior en Chile: el fracaso del Modelo Neoliberal. Límite. Revista Interdisciplinaria de Filosofía y Psicología, 11(37), 21-48.

Bello, A. (1843). Facsímil discurso Instalación de la Universidad. Revista Anales de la Universidad de Chile, 1, 139-152.

Berman, M. (1998). Todo lo sólido se desvanece en el aire. La experiencia de la modernidad. México D.F.: Siglo XXI.

Bonvecchio, C. (1991). El mito de la universidad. México D.F.: Siglo Veintiuno. 
Braidotti, R. (2004). Metamorfosis. Hacia una teoría materialista del devenir. Madrid: Akal.

Brunner, J. J. (1986). Los debates sobre la modernidad y el futuro en América Latina. Documento de Trabajo, 293. Santiago: FLACSO.

Castro-Gómez, S. (2017). Decolonizar la universidad. La hybris del punto cero y el diálogo de saberes. En Z. Palermo (comp.). Des/colonizar la universidad (pp. 69-83). Buenos Aires: Ediciones del Signo.

Derrida, J. (1984). La filosofía como institución. Barcelona: Ediciones Juan Gránica.

Derrida, J. (2010). Universidad sin condición. Madrid: Mínima Trotta.

Devés, E. (2000). Del Ariel de Rodó a la CEPAL (1900-1950). Buenos Aires: Biblos y Centro de Investigaciones Barros Arana.

Díaz, C. (2018). Entrevista a Javier Pinedo. No sé cuántas páginas hay ahí, no muchas, pero creo que tenemos algo. Universum. Revista de Humanidades y Ciencias Sociales. Número Homenaje a Javier Pinedo, 235-256.

Didriksson, A. (2014). La universidad en la sociedad del conocimiento: hacia un modelo de producción y transferencia de conocimientos y aprendizajes. Avaliação (Campinas) [online], 19(3), 549-559.

Figueroa, M. (2011). Jorge Millas. El valor de pensar. Santiago: Ediciones UDP.

Friz, C. (2016). La Universidad en disputa. Sujeto, educación y formación universitaria en la concepción liberal. Santiago: Ceibo.

Giannini, H. (2011). Prólogo. En M. Figueroa. Jorge Millas. El valor de pensar (pp. 17-27). Santiago: Ediciones UDP.

Giannini, H. (2015). Giannini Público. Entrevistas-Columnas-Artículos. Vicerrectoría de Extensión y Comunicaciones de la Universidad de Chile y Facultad de Filosofía y Humanidades de la Universidad de Chile (eds.). Santiago: Editorial Universitaria.

Jaksic, I. (1989). Academic Rebels in Chile: The Role of Philosophy in Higher Education and Politics. Albany: State University of New York Press.

Kant, I. (1963). El conflicto de las Facultades. Buenos Aires: Losada.

Las Heras, J. (2009). El grito de Córdoba: La reforma Universitaria de 1918 y su vigencia en la Universidad del siglo XXI. Santiago: Editorial Universitaria.

Letelier, V. (1912). Filosofía de la Educación. Segunda edición aumentada y corregida. Santiago y Buenos Aires: Editores Juan Nascimiento y Cabout y Cía, Imprenta Cervantes.

Lyotard, J. F. (1989). La condición posmoderna. Informe sobre el saber. Madrid: Cátedra.

Mignolo, W. (2003). Historias locales/diseños globales. Colonialidad, conocimientos subalternos y pensamiento fronterizo. Madrid: Akal.

Mignolo, W. (2017). La retórica de la modernidad y la lógica de la colonialidad. Desobediencia epistémica. Retórica de la modernidad, lógica de a colonialidad y gramática de la descolonialidad (pp. 18-45). Buenos Aires: Ediciones del Signo.

Millas, J. (1981). Idea y defensa de la universidad. Santiago: Editorial del Pacífico. 
Palermo, Z. (2017). Itinerario. Des/colonizar la universidad. ( $1^{\circ}$ edic., pp. $15-$ 35). Buenos Aires: Ediciones del Signo.

Pinedo, J. (2012). El nacimiento de una nueva universidad en el Valle Central y la amputación de las sedes regionales de la Universidad de Chile: el caso de la Universidad de Talca. Revista Anales, 4, 59-75.

Prado, P. (2009). Le Principi D’Université. Paris: Nouvelles Éditions Lignes.

Quijano, A. (2014). Colonialidad del poder, eurocentrismo y América Latina. Cuestiones y horizontes: de la dependencia histórico-estructural a la colonialidad/descolonialidad del poder. Buenos Aires: CLACSO.

Rama, A. (2004 ). La ciudad letrada. Santiago: Tajamar.

Ruiz, C. (1975). Moderación y filosofía. Teoría, 5-6, 15-39.

Sánchez, C. (1992). Una disciplina de la distancia. Institucionalización universitaria de los estudios filosóficos en Chile. Santiago: CERC-CESOC.

Sánchez, C. (2010). Institucionalidad de la Filosofía, entre la reflexión y el conocimiento productivo, Revista Mapocho, 67, 373-385.

Sánchez, C. (2015). Escenas de las escrituras frías, pasionales e inútiles. En A. Kottow y S. Massmann (eds.). Tiempos fundacionales. Nación, identidades y prácticas discursivas en las letras latinoamericanas (pp. 37-55). Santiago: Universidad Andrés Bello y Ril.

Santiago, S. (2012). El entre-lugar del discurso latinoamericano. Una literatura en los trópicos. Ensayos de Silviano Santiago (traducción, presentación y edición de Mary Luz Estupiñán y Raúl Rodríguez). Santiago: Escaparate.

Santos Herceg, J. (2012). Tiranía del paper. Imposición institucional de un tipo de discurso. Revista Chilena de Literatura, 82, 197-217.

Scherz, L. (1988). Reforma y Contrarreforma en la Universidad Católica de Chile (1967-1980). El Centenario de la UC. Realidad Universitaria, 6, 36-51.

Stiegler, B. (2012). État de choc. Bêtise et savoir au XXI siècle. Paris: Mille et Une Nuits.

Thayer, W. (1996). La crisis no moderna de la universidad moderna. Santiago: Cuarto Propio.

Vermeren, P. (2009). Victor Cousin. El juego político entre la filosofía y el Estado. Rosario: Homo Sapiens.

Zea, L. (1968). El positivismo en México. México D.F.: Fondo de Cultura Económica. 